\title{
Analysis and Research on Sound Connection of Wired Headset
}

\author{
Liu Guo-qing
}

\author{
Wenzhou Vocational \& Technical College, Wenzhou. 325035 \\ 3685424@qq.com
}

Keywords: Wired; Headset; Analysis; Ergonomics.

\begin{abstract}
This design is a research on optimizing and improving the portable type of headset. It analyzes both physiological and psychological demands of the users through combining with relevant theories of ergonomics, humanized design and design psychology, and then explores a feasible scheme which is more in line with humanized design requirements of the youth. I finally design a portable folding headset after taking investigation and analysis, and the breakthrough in modeling brings a atmosphere which is not to stick to one pattern to this headset. I fully understand the mental demands of consumers and create products belong to their own for different groups.
\end{abstract}

\section{Introduction}

With the progress of times and the development of society, people have a increasingly high demand for living standard and they begin to pursue real taste of life. Especially for these youth groups, they all have an unruly heart and new things always give them a full and delightful enjoyment. According to the investigations and analysis on current headset market, most related products are inheriting the features of traditional headset and there is no innovation which can attract the attention of consumers. This design changes the mindset of consumers and brings a different kind of enjoyment to contemporary young people.

\section{Market investigation}

Market prospect for portable headset: portable headset refers to a headset with carrying elements which is generally head wear type. Apart from mainstream computer headset and hot WIFI headset, all the manufacturers are seeking for variable product design ideas. They hope to refine the market and get new market growth points. Under the background of such industry thinking, the product line of portable headset increased rapidly in the past year and its market is relatively large.

\subsection{Consumer psychology of the youth}

Young people can be divided into two groups: one group must be the people who are still reading or studying in the campus, they have no work or any social, work pressure, their economy is not yet independent. As a result, we call them "pure consumer group"; the other group must be the people who have already worked, they have a certain independence in economy as well as relatively strong purchasing power, and we call them "production and consumption group". These two groups we mentioned above may have differences in purchasing power, while their purchasing psychology and purchasing behaviors are still the same. They mainly have the following features: 1) The pursuit of personality and fashion. Young people are always full of hope for the future, they are full of curiosity for new knowledge and things in reality, and they also have the courage to pursue. At the same time, they are always occupying the center position in the family and will receive much attentions in future growth, a self centered value is very likely to form. As a result, they often tend to self consumption requirements when shopping -- "What I choose is what I like". Both pleasure and sense of achievement become the focuses in their consumption process, no matter how much they make, their consumption consciousness can not be left behind. 2 ) Advanced consumption habit. Young people always maintain an optimistic attitude to consumption, "use today's money to realize the dream of tomorrow" has become their true portrayal. They have an optimistic attitude about the future and are used to accept installment, overdraft of 
credit card and other cards as well as the consumption patterns of "moonlight clan" and "clear family". What they pursue is the quality of life rather than the saving amount in their bank accounts. 3 ) Pay attention to group consciousness. The consumption consciousness of young people is often affected by the people around who have the same features or value orientations with them, they regard the people they appreciate as the reference of their own behaviors. These reference materials are their "opinion leader" and they cultivate themselves according to the consumption patterns of such

leader.

4) Strong brand sense of belonging. Young people's attitude to the brand depends on their self evaluations as well as the generated brand sense of belonging rather than the attitude of community. For the products they like, they will deem that "this is my brand" and then generate a strong recognition and loyalty. While for these products they do not like, they will ignore. 5) "New" luxury doctrine. Different from the conspicuous consumption of upstart, young people pursue high quality life and advanced consumption concept more. They have surpassed the functional requirements of products in consumption process and are more tend to the products and services with better quality and higher taste. This is the fulfill of pursuing the quality of life as well as fashion consumption attitude rather than conspicuous consumption.

\subsection{Huge consumption capacity of young people}

The youth have amazing purchasing power as well as huge consumption potential. This is not just because of the number advantage of the youth and the greater reason is that they have extensive consumer demands and rich consumer contents. International statistics data shows that the youth occupies about $1 / 5$ of the total population in the world. Wherein, the number of young people in China is nearly 300000000 which occupies about $1 / 4$ of domestic population number. This indicates that young people are absolutely a huge consumer group. Seeing from the purchase requirements of youth, initial stage is the golden time for growth and development, they need adequate nutrition to complement their physiological demands, and these food with high fat, high protein and high energy are widely welcomed by the youth. After the middle and late stages of the youth, their daily social activities, especially their communications with the opposite sex become more and more frequent. They all have a strong demand for the consumer products which can meet their demand such as: fashionable dress, cosmetic, audio, video photography, movie tickets, tickets for sports competitions, literature and art novels, tourism as well as various fashionable and leisure products. Before entering marriage, they form the peak period of consumption for purchasing wedding supplies. Consumer expenditure on other aspects at this time is much higher. As a result, we can say without any exaggeration that young people's strong demand for consumer products is far beyond our imagination. The products meet both the physiological demands of the low level as well as psychological, spiritual and cultural demands of the higher level are the objects of youth consumption.

\section{Analysis and design}

With the rapid expansion of $2.4 \mathrm{GHz}$ wireless technology in headset area, RAPOO, Bingo, charm, Ou Fan lattice and other manufacturers launch a variety of products whose price is lower than 300 yuan, wherein, some products only are sold at a price of 99 yuan which breaks the situation of the exorbitant price of wireless headset and receives attentions from many users. Under the promotion of increased product number, decreased price and other factors, wireless headset will transfer from concept introduction stage to substantial contest stage of market share. Common types of headset on the market are: portable wearing headset, headset, rear hanging earphone, supra-aural earphone and WIFI headset. Wherein, headset has the least damage to our ears. Compared to ear hanging ones, although headset has no advantage of small and portable, it has a very good sound effect. What is more, because we do not need to put it into our ears, it does no harm to the ear canal and eardrum. 


\subsection{Portable headset}

It also belongs to the head-mounted earphones and has a "thick body". The biggest feature of head-mounted earphones is the excellent sound insulation as well as good sound quality. These headset can not be folded and are not easy to carry, although they can provide a pretty good sound insulation effect, it is not suitable for travel.

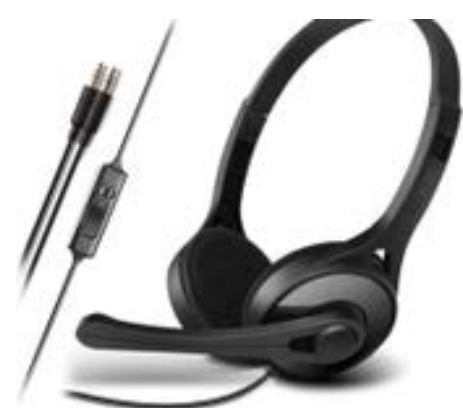

Figure 1 With a microphone

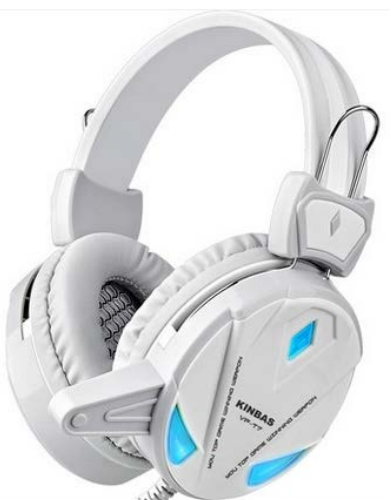

Figure 2 Head wearing type

Not all the headset have portable ability, as a result, apart from portable ones, there are standard wearing headset. The characteristics of this type is that the unit size is bigger which can almost wrap the whole ears. In addition, its structural frame is thick and it is the product that only used indoor.

\subsection{Ear-hook and neck-back headset}

Although traditional headset has rich types, the design of head beam is a nightmare to those people who have special hair styles. As a result, the emergency of ear-hook and neck-back headset solve this problem. Of course, they have the same advantages and disadvantages with ear-hook earplug, they have serious sound leakage problem which still remains unresolved in nowadays. SONY EQ series are the more common ear-hook headset, while neck-back headset are mainly sports ones. Both of them occupy lower market share and the prices are relatively cheap.

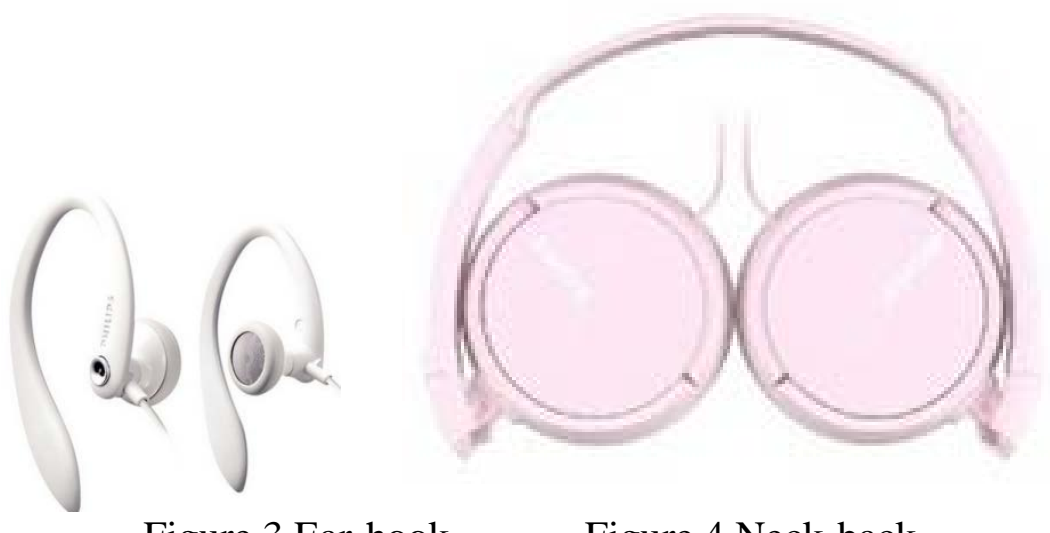

\subsection{Appearance design}

Figure 3 Ear-hook

Figure 4 Neck-back

Insert the headset and then rotate to the required time scale, the headset will start music and begin to count down. Scale line of the headset will return back after several times. In addition, we may also turn off the music through rotating to complete timing function which is shown as figure 5 , and the plug size chart is shown as figure 6 .
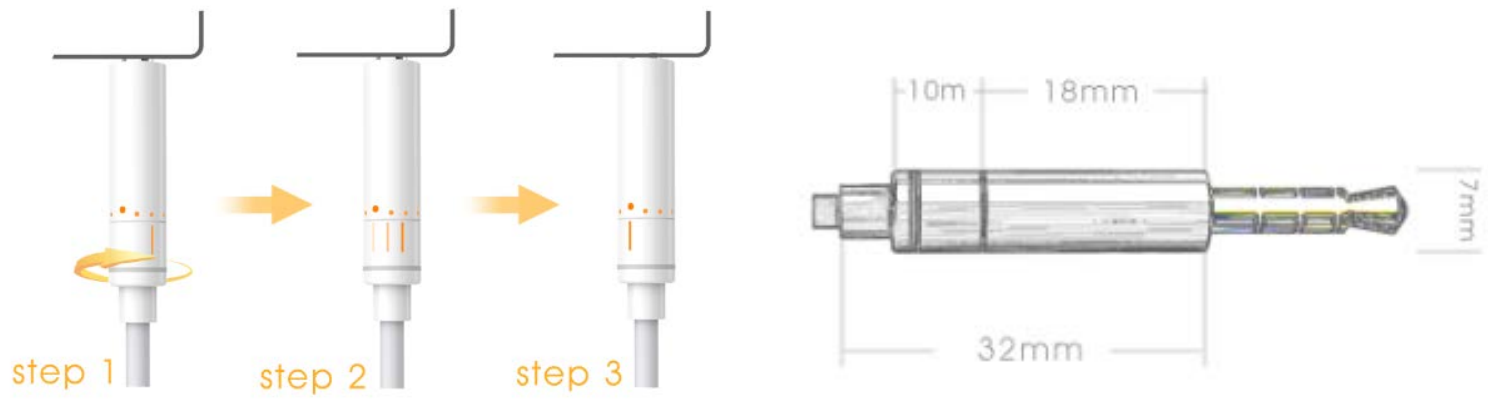
Figure 5 Rotation timing function Figure 6 Plug size chart

A headset mainly consists of four parts: left and right voice unit, headband, lead wire and ear muffs. Headband is mainly used for fixing left and right voice unit and hanging them on your ears. Pressure on the head from headband and ear muffs depends on the structure as well as the connecting mode with the units, meanwhile, it also determines the wearing comfort. Ear muffs are placed between head and voice unit, and this is very important to moving coil headset. It can reduce low-frequency reflection and guarantee the playback of low-frequency. Generally speaking, there are two kinds of ear muffs, one is that we can cover on the ears which is called ear-pressure one; the other is cupped which surrounds our ears. Insert effect is shown as figure 7 and computer simulated analysis is shown as figure 8 .

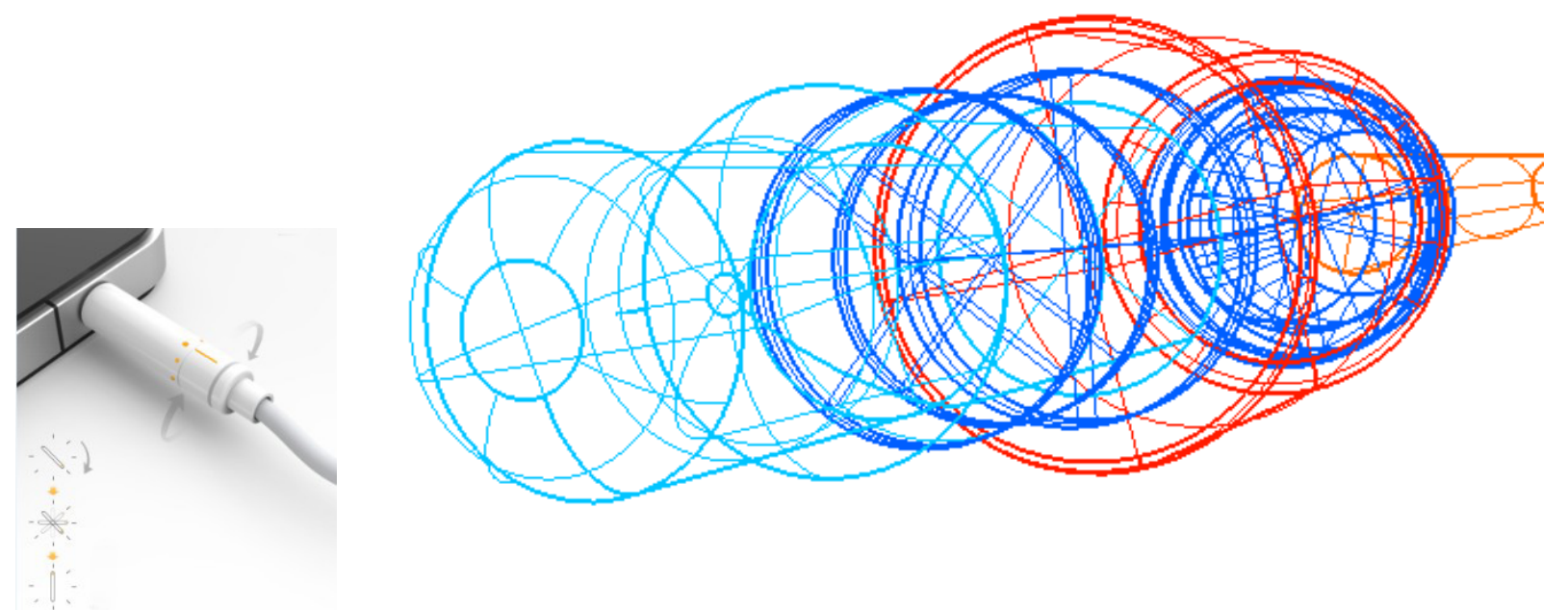

Figure 7 Insert effect Figure 8 Computer simulated analysis

\section{Summary}

This design mainly modifies the use manner of headset which reflects the portable part best. I use the cool automobile hubs as the vocal units on both sides. The novel folding method achieve the purpose of portability when maintaining the fashion sense. It has beyond mere folding and adds the elements of movement as well as more folding structure. In addition, there are various methods available for selection.

\section{References}

[1] DAI Hong-min, DAI Pei-hua.Goal, Principles and Methods of Product Complete Packaging Solutions[J].Journal of Chongqing Technology and Business University（Social Science Edition）, 2007, 27 (1) : 81-82.

[2] LI Jun.New Concept of Packaging: Complete Packaging Solutions[J].China Packaging Industry, 2006 (2) : 33.

[3] LE E S ang-yoon, CHEN Ti an , KIM Jong-seo, et al.Using Vi rtual Reali ty for Evalu at ing Af f ective Propert ies of Product Design[ C] .USA :IE EE V R 2004 Conf erence , 2004.

[4] SUH Ki-Soo , LEE You ng Eun .Th e Rol e of Vi rtual Experience in Consum er Learning :An Em perical Invest igation [ J] .MIS Qu artly , 2005 , 29(4):115 -143 .

[5] WANG Liang-shen, SUN Feng-hua.TRIZ Innovation Theory and Application Principles[M].Beijing: Science Press, 2010.

[6] GAO Li-wen.The Function of Packaging Optimum Design in Modern Logistics[J].China Logistics \& Purchasing, 2012 (5) : 58. 